\title{
Sistem Informasi Geografis Distribusi Mahasiswa Kuliah Kerja Nyata Universitas Sembilanbelas November Kolaka
}

\author{
Arysespajayadi $^{1}$, Kharis Syaban ${ }^{2}$ \\ ${ }^{1,2}$ Program Studi Ilmu Komputer, Fakultas Teknologi Informasi \\ ${ }^{1,2}$ Universitas Sembilanbelas November Kolaka, \\ Jl. Pemuda No.339 Kolaka, Sulawesi Tenggara \\ Email : arysespajayadi@gmail.com ${ }^{1}$, k.syaban@gmail.com ${ }^{2}$
}

\begin{abstract}
ABSTRAK
Kuliah Kerja Nyata merupakan salah satu mata kuliah yang wajib diselesaikan oleh mahasiswa disuatu perguruan tinggi sebagai bentuk pengabdian masyarakat. Sistem pendataan terhadap lokasi diperlukan sebuah sistem dalam bentuk informasi geografis. Sistem Informasi Geografis dapat menampilkan tempat secara langsung mengenai lokasi mahasiswa dan dosen pembimbing. Perancangan sistem menggunakan bahasa pemrograman PHP dan database My-SQL serta untuk sistem pemetaan menggunakan Google Maps API yang dapat menampilkan informasi geografis bumi melalui bantuan koneksi internet ke server Google. Data yang digunakan adalah data mahasiswa, dosen pembimbing, dan tempat mahasiswa kuliah kerja nyata. Hasil penelitian yang telah dicapai adalah sistem dapat menampilkan informasi tempat berupa rute menuju tempat, dosen pembimbing serta informasi nama mahasiswa yang mengikuti kegiatan Kuliah Kerja Nyata.
\end{abstract}

Kata Kunci : Sistem Informasi, Google Maps API, KKN, Geografis

\section{ABSTRACT}

Real Work Lecture is one of the courses that must be completed by students at a university as a form of community service. The data collection system for the location requires a system in the form of geographic information. The geographic Information System can display the location directly regarding the location of students and supervisors. The system design uses the PHP programming language and My-SQL database as well as for the mapping system using the Google Maps API which can display the earth's geographic information through the help of an internet connection to a Google server. The data used are student data, supervising lecturers, and the location of real work students. The results of the research that have been achieved are the system can display location information in the form of routes to the location, supervisors, and information on the names of students who take part in Real Work Lecture activities.

Keywords : Information System, Google Maps API, KKN, Geographic

\section{PENDAHULUAN}

Dalam dunia pendidikan pada perguruan tinggi, mahasiswa sebagai objek yang sangat berpengaruh dalam kehidupan masyarakat. Hal ini tidak lepas dari keilmuan 
seorang mahasiswa yang diperoleh di perguruan tinggi. Banyak hal yang bisa diimplementasi keilmuan seorang mahasiswa dilingkungan masyarakat, salah satunya yaitu dengan melakukan pengabdian masyarakat. Perguruan Tinggi juga mengwajibkan suatu mata kuliah yang harus mahasiswa selesaikan yaitu mata kuliah kerja nyata atau disingkat KKN.

KKN memiliki dampak yang cukup penting bagi mahasiswa, seperti membentuk sikap kepedulian sosial dan tanggung jawab mahasiswa terhadap kemajuan masyarakat, memberikan pengalaman dan keterampilan kepada mahasiswa sebagai kader pembangunan, serta membina mahasiswa agar menjadi seorang inovator dan motivator. Bagi pemerintah daerah dan masyarakat setempat, kegiatan $\mathrm{KKN}$ dapat membantu percepatan proses pembangunan serta membentuk kader penerus kegiatan pembangunan (Setiawan, 2019).

Menurut (Fandatiar, 2015) dengan adanya KKN, mahasiswa diharapkan dapat mengaktualisasikan disiplin ilmu yang masih dalam tataran teoritis dengan bentuk pengabdian dan pendampingan langsung kepada masyarakat, disamping penelitian yang dilakukan sebagai usaha pengembangan ilmu yang didapat sebelumnya.

Namun terkadang dalam pelaksanaan KKN biasanya terjadi kurangnya informasi yang didapatkan mahasiswa mengenai tempat atau lokasi KKN yang berada di daerahdaerah, dimana mahasiswa belum pernah mengetahui tempat tersebut secara detail. Hal ini perlunya sebuah sistem informasi yang berkaitan dengan informasi lokasi KKN secara detail.

Untuk mengetahui sistem informasi lokasi $\mathrm{KKN}$ diperlukan sistem informasi geografis. Sistem Informasi Geografis (SIG) merupakan sistem informasi berbasis komputer yang digunakan untuk mengolah dan menyimpan data atau informasi berbasis geografis (Annugerah, 2016).

Penelitian SIG ini telah banyak dilakukan oleh peneliti lain, beberapa penelitian dengan studi kasus yang berbeda-beda, seperti penelitian rancang bangun sistem informasi kuliah kerja nyata (e-kkn) universitas respati Yogyakarta (Sri, 2020). Serta penelitian Sistem Informasi Geografis Wilayah Kampus Universitas Mulawarman Menggunakan Google Maps API oleh (Rosdania, 2016).

Dari landasan tersebut Universitas Sembilanbelas November Kolaka (USN Kolaka) setiap tahun ajarannya, menurunkan mahasiswa untuk pengabdian masyarakat 
melalui KKN ke berbagai pelosok daerah. Besarnya populasi mahasiswa USN Kolaka dalam melakukan KKN sangat diperlukan sebuah sistem geografis berbasis komputer, sehingga sistem informasi geografis bertujuan agar sistem ini dapat mempermudah mahasiswa untuk mengetahui lokasi secara detail tempat KKN.

\section{METODE PENELITIAN}

\section{Teknik Pengumpulan Data}

Menurut (Effendy \& Sunarsi, 2020) mengemukakan bahwa Teknik Pengumpulan Data adalah teknik utama pada suatu penelitian, berawal dari memperoleh suatu data merupakan maksud utama dari adanya suatu penelitian, tanpa mengenal dari teknik pengumpulan data, sudah dapat dipastikan bahwa peneliti tidak dapat memperoleh data yang bisa melengkapi standar dari data yang telah ditetapkan. Pada penelitian ini penulis menggunakan tiga teknik pengumpulan data menurut (Rada, 2021). diantaranya:

1. Observasi, teknik pengumpulan data dengan cara melakukan pengamatan langsung pada kondisi ataupun situasi pada suatu subjek pada penelitian.

2. Wawancara, teknik pengumpulan data ini dilakukan dengan mengemukakan sebuah pertanyaan ataupun tanya jawab langsung pada subjek penelitian.

3. Studi Pustaka, teknik pengumpulan data dengan menggunakan buku, jurnal ilmiah, ataupun berbagai jenis sumber yang kredibel dan relevan dengan penelitian sistem informasi geografis.

\section{HASIL DAN PEMBAHASAN}

\subsection{Perancangan Data Flow Diagram}

\section{Diagram Konteks}

Dalam proses pengembangan desain sistem informasi geografis distribusi mahasiswa kuliah kerja nyata universitas sembilanbelas november kolaka, digunakan model berupa metode berarah aliran data menggunakan Data Flow Diagram (DFD). Desain ini dimulai dari bentuk yang paling umum digunakan yaitu diagram konteks. Diagram konteks ini kemudian akan di turunkan sampai bentuk yang paling detail. Dalam pembuatan diagram konteks perlu di analisis sistem yang akan di bangun, sumber data dan tujuan ataupun hasil akhir yang di inginkan. Dari hasil analisis tersebut, diperoleh diagram konteks sebagaimana ditunjukkan pada gambar berikut. 


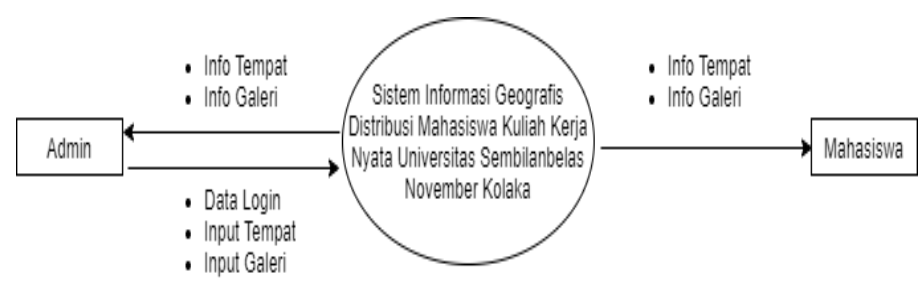

Gambar 1: Diagram Konteks (DFD Level 0)

Aliran data bersumber dari admin, yang memasukan data dan mengolah data sehingga kemudian data yang diolah tersebut disajikan ke dalam sistem informasi geografis, diantaranya informasi tempat dan informasi galeri, sehingga isi dari masukan admin dapat dilihat oleh mahasiswa.

\section{Data Flow Diagram Level 1}

Data Flow Diagram level 1 merupakan pengembangan dari diagram konteks yang terdiri dari dua proses yaitu proses login, proses pengolahan data Tempat dan proses data Galeri. Data Flow Diagram Level 1 ini ditampilkan sebagai berikut:

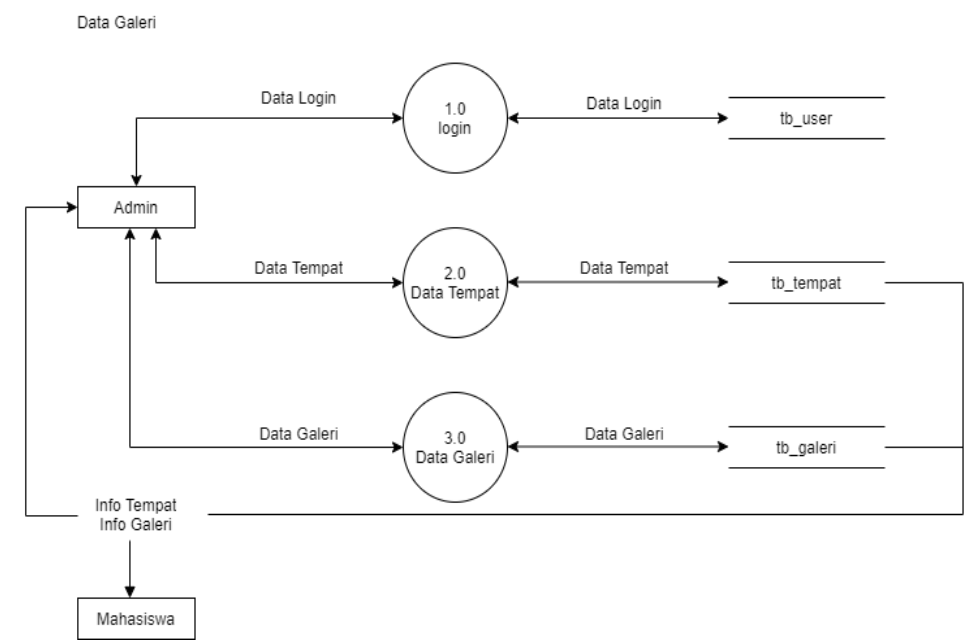

Gambar 2: Data Flow Diagram Level 1

\section{Data Flow Diagram Level 2 Login}

Data Flow Diagram level 2 Login terdiri dari dua buah proses. Prosesnya antara lain ubah data, dan simpan data. DFD Level 2 Login dapat dilihat pada Gambar di bawah ini. 


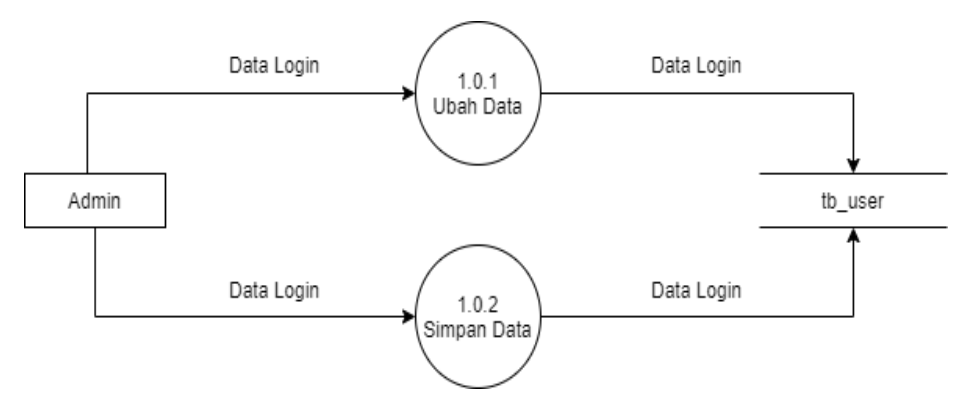

Gambar 3: Data Flow Diagram Level 2 Login

\section{Data Flow Diagram Level 2 Pengolahan Data Tempat}

Data Flow Diagram level 2 Pengolahan Data Tempat terdiri dari empat buah proses. Prosesnya antara lain ubah data, hapus data, tambah data dan lihat data. DFD Level 2 pengolahan Data Tempat dapat dilihat pada Gambar di bawah ini.

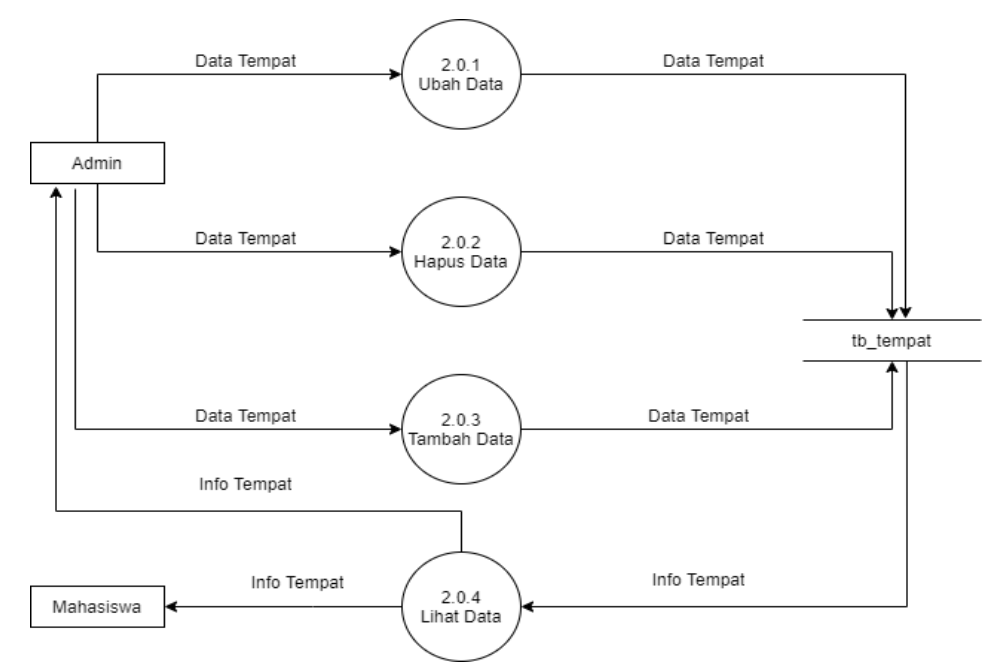

Gambar 4: Data Flow Diagram Level 2 Pengolahan Data Tempat

\section{Data Flow Diagram Level 2 Pengolahan Data Galeri}

Data Flow Diagram level 2 Pengolahan Data Galeri terdiri dari empat buah proses. Prosesnya antara lain ubah data, hapus data, tambah data dan lihat data. DFD Level 2 Pengolahan Data Galeri dapat dilihat pada Gambar di bawah ini. 


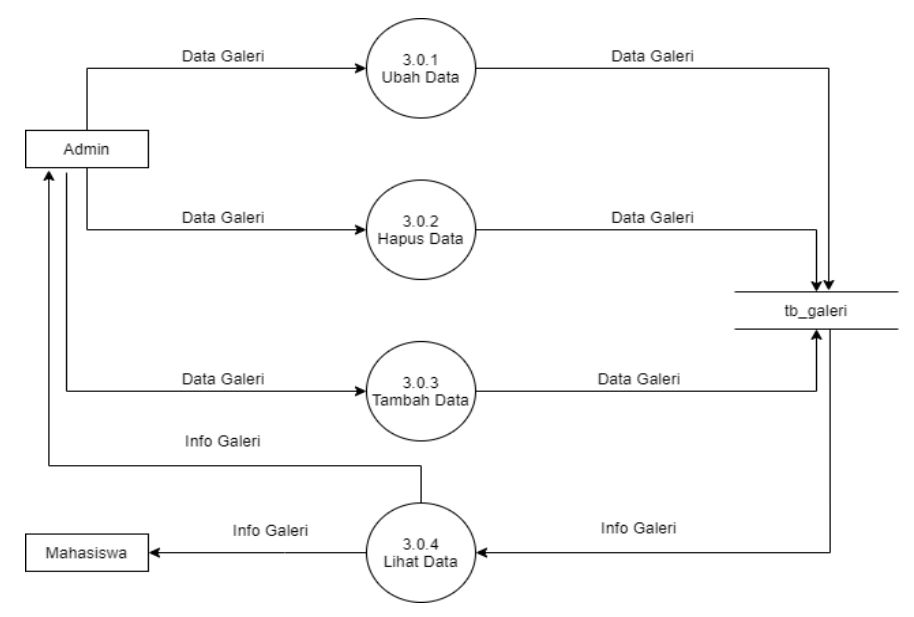

Gambar 5: Data Flow Diagram Level 2 Pengolahan Data Galeri

\subsection{User Interface (UI)}

Untuk mempermudah pengguna dalam memahami sebuah Sistem Informasi Geografis Distribusi Mahasiswa Kuliah Kerja Nyata Universitas Sembilanbelas November Kolaka penulis menerapkan user interface. Desain penerapan rancangan yang diusulkan supaya sesuai dengan keinginan pemakai dan memberikan solusi pada permasalahan yang terjadi. Agar rangkaian elemen mudah dipahami dan diakses User Interface (UI) digunakan sebagai sebuah fasilitas dari langkah untuk mengantisipasi apa sedang dilakukan oleh pemakai (Hidayat \& Hati, 2021).

\section{User Interface Halaman Utama.}

Halaman ini berisi informasi mengenai kegunaan website ini dan informasi tempat KKN secara keseluruhan di tiap wilayah. 


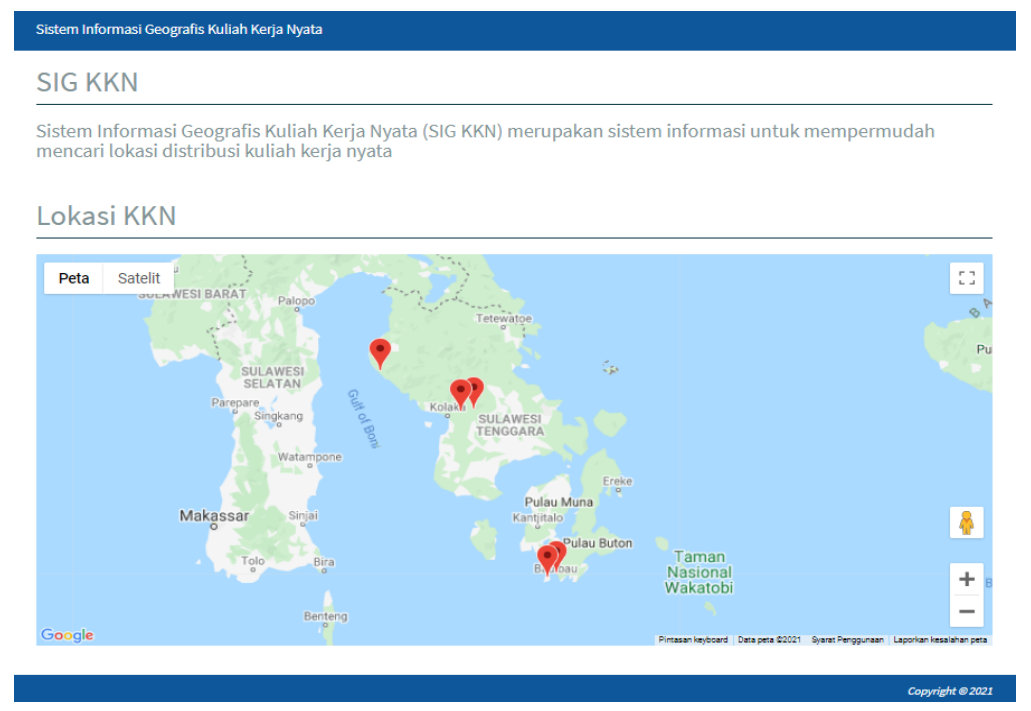

Gambar 6: User Interface Halaman Utama.

Apabila user memilih titip kordinat sebuah peta yang berada di halaman utama, maka website memberikan sebuah informasi mengenai nama tempat KKN tersebut, untuk lebih jelasnya dapat dilihat pada gambar berikut ini.

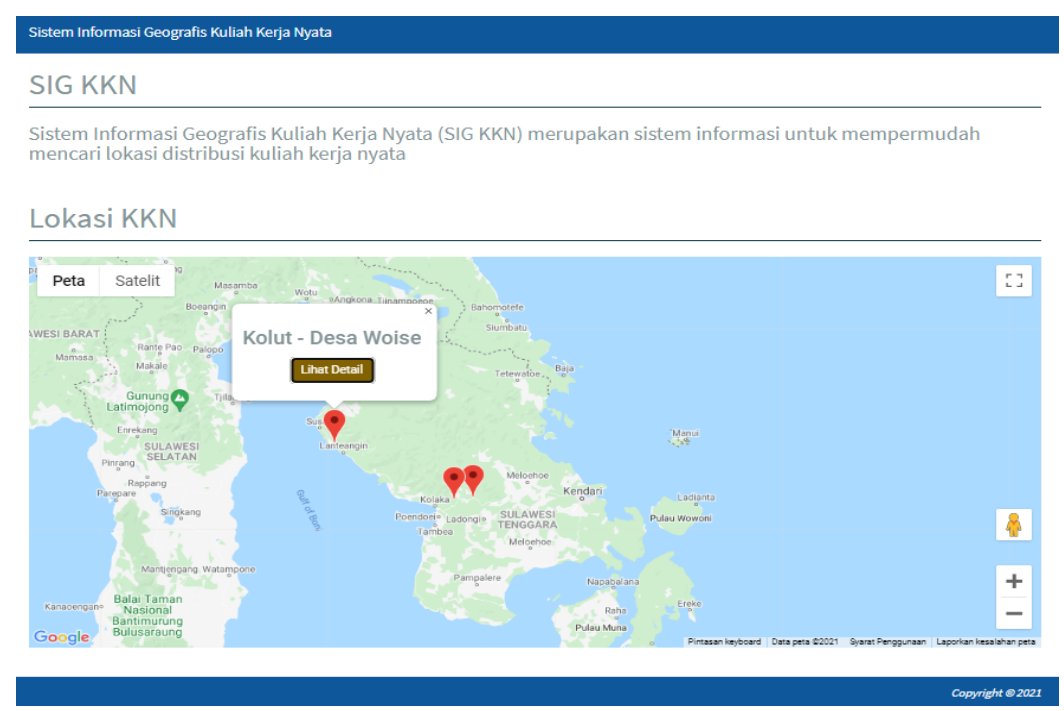

Gambar 7: User Interface Nama Tempat.

Pada gambar 7 nama tempat KKN telah tampil berupa nama kabupaten dan nama desa, sehingga untuk informasi lebih jelasnya, user dapat mengklik tombol lihat detail, yang dimana akan menampilkan berupa detail tempat $\mathrm{KKN}$, untuk melihat tampilan tempat secara detail, dapat dilihat pada gambar 10 .

Selanjutnya, Halaman Login Admin. Admin dapat melakukan login pada sistem 
informasi geografis untuk melakukan input tempat, input galeri dan perubahan password admin. Berikut ini halaman login admin, dapat dilihat pada gambar berikut ini.

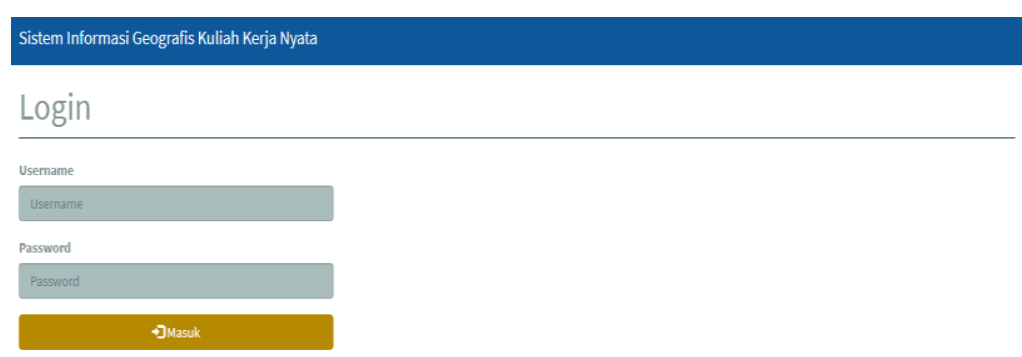

Gambar 8: Halaman Login Admin

\section{Halaman Penginputan Tempat}

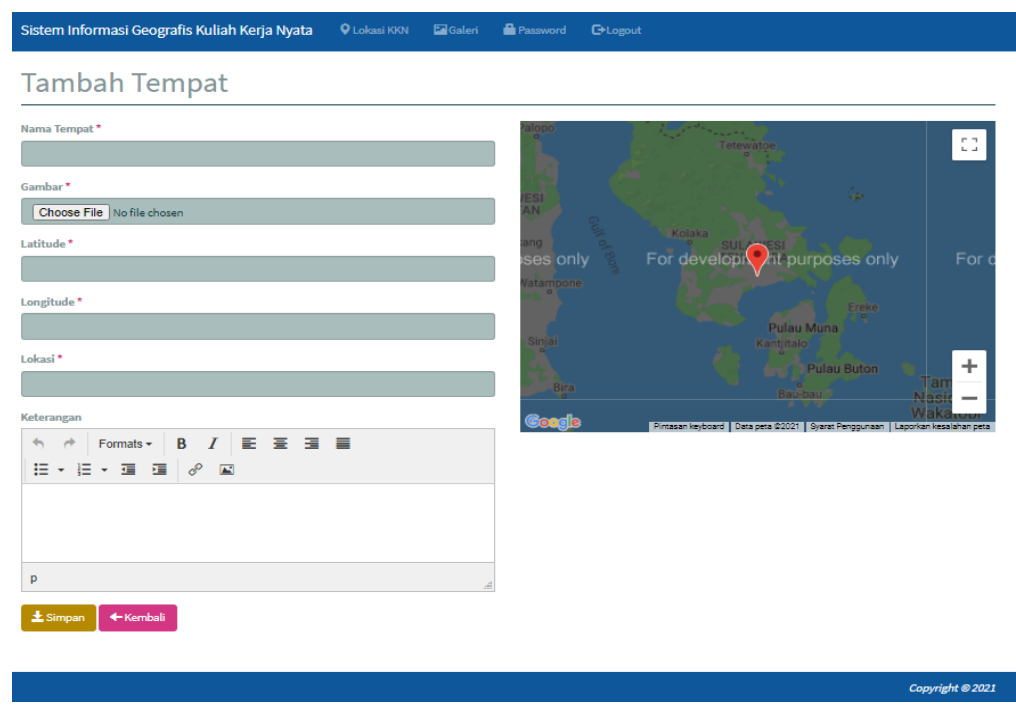

Gambar 9: Halaman Input Tempat

Pada halaman ini Admin menginput nama tempat, gambar, titip kordinat tempat KKN dengan mengambil data Latitude dan Longtitude, lokasi, dan keterangan yang dapat diisi berupa nama dosen pembimbing serta nama mahasiswa KKN. 


\section{Halaman Detail Tempat}

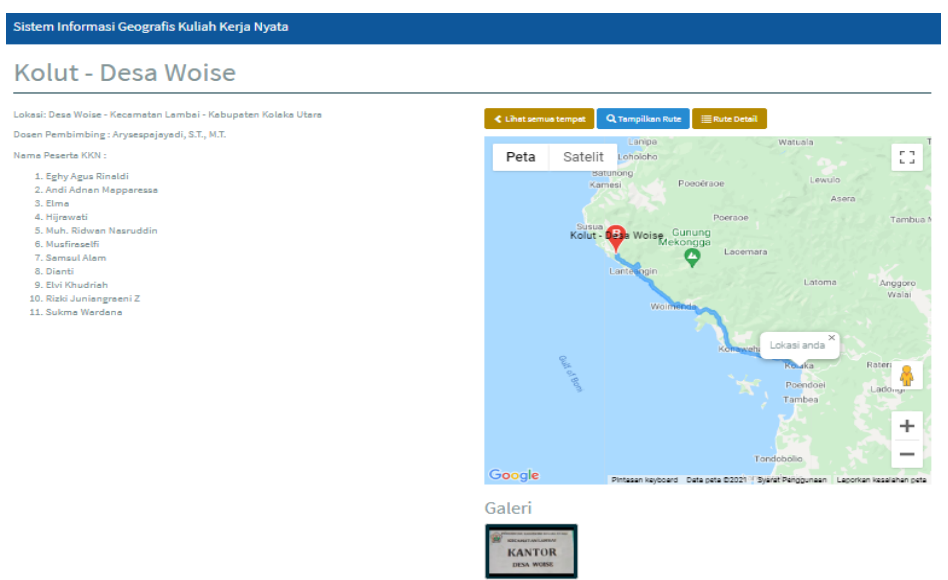

Gambar 10: Halaman Detail Tempat

Halaman ini merupakan halaman tempat secara detail, dimana user atau mahasiswa dapat melihat informasi jalur menuju tempat KKN dan informasi berupa nama tempat KKN, nama dosen, dan nama peserta KKN.

\section{Halaman Rute Tempat}

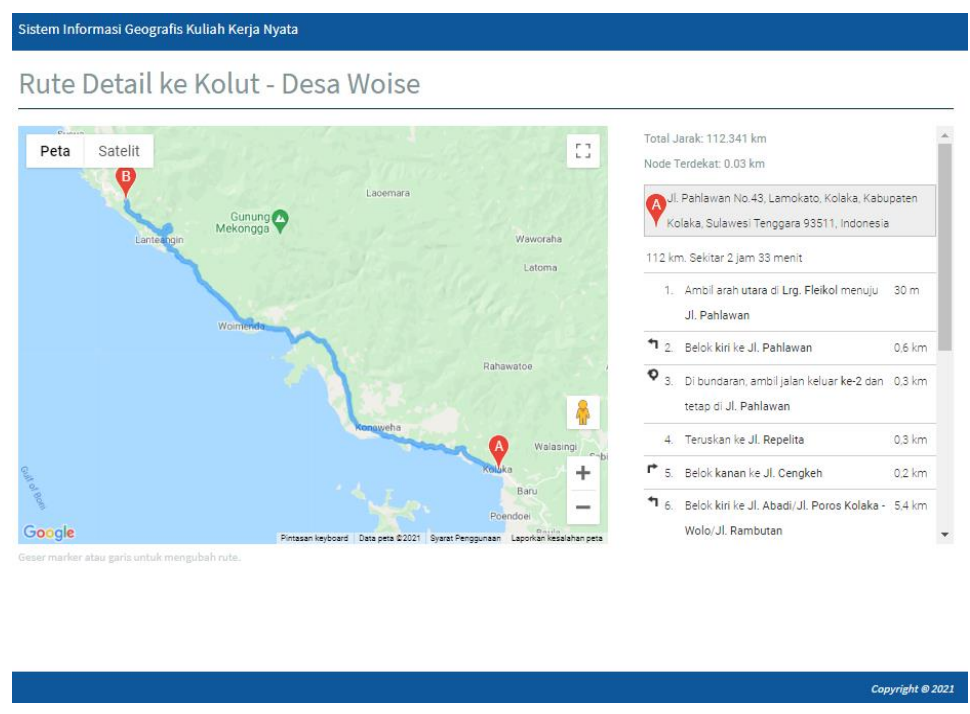

Gambar 11: Halaman Rute Detail Tempat

Halaman rute tempat secara detail merupakan petunjuk arah menuju tempat yang akan dituju untuk mempermudah user atau mahasiswa mendapatkan tempat KKN. 


\section{SIMPULAN}

Sistem Informasi Geografis Distribusi Mahasiswa Kuliah Kerja Nyata Universitas Sembilanbelas November Kolaka dapat disimpulkan bahwa dengan adanya website informasi mengenai tempat KKN dapat mempermudah user atau mahasiswa mencari tempat KKN serta dapat mengetahui nama dosen pembimbing dan nama-nama peserta KKN. Pada sistem tersebut user atau mahasiswa juga dapat sebuah informasi berupa rute atau jalur secara detail menuju tempat KKN. Diharapkan pengembangan sistem kedepannya, dapat dikembangkan atau dibuat sebuah sistem informasi geografis berbasis mobile.

\section{DAFTAR PUSTAKA}

Annugerah, A., Astuti, I. F., \& Kridalaksana, A. H. (2017). Sistem informasi geografis berbasis web pemetaan tempat toko oleh-oleh khas Samarinda.

Effendy, A. A., \& Sunarsi, D. (2020). Persepsi Mahasiswa Terhadap Kemampuan Dalam Mendirikan UMKM Dan Efektivitas Promosi Melalui Online Di Kota Tangerang Selatan. JURNAL ILMIAH MEA (Manajemen, Ekonomi, Dan Akuntansi), 4(3), 702-714. https://journal.stiemb.ac.id/index.php/mea/article/download/571/248

Fandatiar, G., Supriyono, S., \& Nugraha, F. (2015). Rancang bangun sistem informasi kuliah kerja nyata (KKN) pada Universitas Muria Kudus. Simetris: Jurnal Teknik Mesin, Elektro dan Ilmu Komputer, 6(1), 129-136.

Hidayat, N., \& Hati, K. (2021). Penerapan Metode Rapid Application Development ( RAD ) dalam Rancang Bangun Sistem Informasi Rapor Online ( SIRALINE ). 1, $8-17$.

Mulyani, S. H., Widodo, S. T., \& Hamzah, R. H. (2020). RANCANG BANGUN SISTEM INFORMASI KULIAH KERJA NYATA (E-KKN) UNIVERSITAS RESPATI YOGYAKARTA. In Prosiding Seminar Nasional Multidisiplin Ilmu (Vol. 2, No. 1, pp. 309-320).

Rada. (2021). Teknik Pengumpulan Data. Dosenpintar.com. https://dosenpintar.com/teknik-pengumpulan-data/

Renaldi, T., Raharjo, Y., \& Arum, R. (2013). Perancangan Sistem Informasi Kuliah Kerja Nyata Universitas Lampung Berbasis Web. Jurnal Informatika dan Teknik Elektro Terapan, 1(3).

Rosdania, R., Agus, F., \& Kridalaksana, A. H. (2016). Sistem Informasi Geografi Batas Wilayah Kampus Universitas Mulawarman Menggunakan Google Maps API. Informatika Mulawarman: Jurnal Ilmiah Ilmu Komputer, 10(1), 38-46.

Setiawan, M. A., Muludi, K., \& Irawati, A. R. (2019). Pengembangan aplikasi kkn berbasis android (studi kasus universitas lampung). Jurnal Sistem Informasi dan Sains Teknologi, 1(1). 